Article

\title{
Examining the Role of Childhood Experiences in Developing Altruistic and Knowledge Sharing Behaviors among Children in Their Later Life: A Partial Least Squares (PLS) Path Modeling Approach
}

\author{
Imran Ali ${ }^{1}$, Murad Ali ${ }^{1, *}$, Saeed Badghish ${ }^{1}$ and Thamer Ahmad S. Baazeem ${ }^{2}$ \\ 1 Faculty of Economics and Administration, King Abdulaziz University, Jeddah 21589, Saudi Arabia; \\ imranalinim@gmail.com (I.A.); sbadghish@kau.edu.sa (S.B.) \\ 2 Faculty of Business, and Research and Consulting Institute (RACI), King Abdulaziz University, \\ Jeddah 21589, Saudi Arabia; tbaazeem@kau.edu.sa \\ * Correspondence: mali3@kau.edu.sa
}

Received: 20 October 2017; Accepted: 12 January 2018; Published: 23 January 2018

\begin{abstract}
Previous research on child development advocates that motivating children to make a choice to forfeit their own toys with others develop sharing behavior in later life. Borrowing the conceptual background from the child development theory, this study proposes a model of knowledge sharing behavior among individuals at the workplace. The study proposes a unique conceptual model that integrates the cognitive/behavioral, and other childhood theories to explain the knowledge sharing behavior among individuals. The study uses psychological, cognitive, behavioral and social learning theories to explain the development of altruistic behavior in childhood as a determinant of knowledge sharing behavior. This study develops and empirically tests a research framework which explains the role of childhood experiences in developing altruistic behavior among children and the translation of this altruistic behavior into knowledge sharing behavior later in their professional life. This study explores those relationships using PLS-SEM with data from 310 individuals from Pakistan. The study concludes the role of parents and child-rearing practices as central in developing children's altruistic attitude that leads to knowledge sharing behavior in their later life. The implications and future research directions are discussed in details.
\end{abstract}

Keywords: childhood experiences; parenting practices altruistic behavior; knowledge sharing behavior

\section{Introduction}

During the last few decades, scholarly community provides a platform for discussing challenges pertaining to contemporary issues in innovation and knowledge [1-6]. Innovation and knowledge are considered as crucial organizational asset that provide competitive and sustainable advantage to organizations in today's dynamic business environment [2,4,5,7-14]. Organizations invest significant amount of resources to use knowledge as competitive advantage to increase efficiency and find innovative solutions for customers $[15,16]$. Companies with superior knowledge management systems surpass their peers by translating knowledge into innovative products, services and internal processes [17-19].

Knowledge sharing occupies pivotal role in knowledge management [13]. The success of knowledge management systems depends upon employees' knowledge sharing behavior [13]. Knowledge sharing is important facet of knowledge management because it leads to increased 
exploitation and exploration of knowledge resources by employees and improves innovative performance at individual, team, and organizational levels [13,20-26]. Although organizations invest significant resources in implementing knowledge management systems, knowledge sharing maybe considered as one of the most important failure reasons of knowledge management systems (Babcock, 2004). Therefore, there is call for research to investigate the factors that motivate or facilitate employees to share knowledge, in order to yield superior efficiency from knowledge management systems within organizations [27]. Knowledge sharing is an important concept for academics and business practitioners. An emerging steam of research on knowledge sharing complements a large body of literature that points to identify the determinants of knowledge sharing in different contexts including organizational (management support, reward, organizational structure), interpersonal (team characteristics, diversity, social networks), cultural characteristics (collectivism), motivational factors (knowledge ownership beliefs, perceived benefits, trust, social cost. LMX), and at individual levels (personality traits, self-efficacy, impression management).

Despite the growing interest in knowledge sharing, few capture the richness of the concept [13]. Moreover, while many studies are devoted to outcomes of knowledge sharing, antecedents of knowledge sharing intentions among individuals have been largely ignored [13]. As such this study advances the work of scholars who suggest that cognitive or behavioral factors greatly affect individual's knowledge sharing behavior as planet of research focus on various role of individual characteristics in determining knowledge sharing behavior [13].

The sparse research available that examines the role of childhood experiences in developing knowledge sharing behavior among children in their later life. Although there are some researches available in literature that examine the role of individual characteristics in determining knowledge sharing behavior, very little is known about the cognitive/behavioral factors that influence individual's knowledge sharing behavior [13].

Sharing is a behavioral choice and it is important to study the factors that influence on individual's sharing behavior. The present study expands the understanding of knowledge sharing behavior in multiple ways. First, this study uses behavioral approach to examine the role of cognition in the development of sharing attitude among individuals. According to Chernyak and Kushnir [28] allowing children to make choice to share their toys with others motivate them to share more resources in future. Second, this study takes lead from these findings to explain the knowledge sharing behavior among individuals as a result of sharing attitude developed during their childhood. Third, unlike previous studies that emphasizes on outcomes of knowledge sharing, this study considers knowledge sharing as an outcome of the research model and focuses on antecedents of knowledge sharing. Finally, this study investigates the nature of the relationship among childhood experiences, altruistic behavior and knowledge sharing behavior. This study fills the research gap by offering a unique model that examines the influence of childhood experiences in developing knowledge sharing behavior among children later in their professional life. In particular, the purposes of this study are (1) to examine the effect of (a) parenting educational background, (b) parenting practices (authoritarian, training and authoritative) and finally (c) parenting socialization goals on children altruistic behavior; and (2), to examine the effect of children altruistic behavior on knowledge sharing behavior.

The purposes of this study integrate three main theories which provide the theoretical framework and research model development for this study. This study analyzes the role of childhood experiences (parenting educational background, parenting practices and parenting socialization goals) as an antecedent in the development of children altruistic behavior and knowledge sharing behavior. To the best of our knowledge, no study has previously investigated the role of childhood experiences in developing the children altruistic behavior and knowledge sharing behavior among children in their later life. 
To achieve these objectives, this paper follows the following organization: Section 2 proposes and develops a number of empirically testable hypotheses. Section 3 presents the data and methodology used in this research. Section 4 explains the results. Finally, Section 5 discusses the implications of this study, presents some limitations, and establishes various lines for future research.

\section{Theoretical Background and Hypotheses}

\subsection{Knowledge Sharing Behavior}

There is lack of consensus on commonly agreed definition and the use of different models and theories of knowledge sharing [29]. There are also different concepts that are normally confused with knowledge sharing, for instance, knowledge exchange (includes knowledge sharing and knowledge seeking i.e., employees searching for knowledge from others), and knowledge transfer (sharing of information by the knowledge source and application of knowledge by the recipient). The current study considers the definition of knowledge sharing associated with Cummings [22], and Pulakos, Dorsey and Borman (2003). According to Cummings, (2004) and Pulakos, Dorsey and Borman [30] knowledge sharing means providing the information or know-how to the relevant persons, helping others (by provision of knowledge) to solve their problems and collaborating others to develop new ideas or implementation of procedures or policies.

Knowledge management is a vast field and plenty of research has addressed different aspect of knowledge management ranging from individual to group to organizational levels. The role of organizational systems including; HRM practices to organizational behavior to use of information communication technology (ICT) have been examined to exploit the potential of knowledge management to improve performance at various levels in the organizations. A number of authors have examined the benefits of knowledge managements to improve organizational efficiency and effectiveness in different contexts. For instance, most recently Centobelli, Cerchione and Esposito [31] explain the usefulness and alignment of knowledge management systems in management decision support systems to improve the effectiveness performance of hi-tech small and medium organizations. Some studies examine the psychological factors that influence the knowledge sharing intentions of employees. For instance, Chen, Chuang and Chen [32] holds that knowledge sharing self-efficacy and organizational climate positively influence the knowledge sharing intentions of employees. Considering the significance of knowledge management, the organizations have devised their incentives to motivate their employees to generate, share, store and apply more knowledge to improve their individual as well as organizational performance. In this connection, Zhang, Pablo and Zhou [33] highlight the importance of incentive-based relationships and IT-based environment to increase employees' participation in knowledge management visualization in the organizations. Oher studies such as Pee and Min [34] postulates the significance of good employee-environment fit to strengthen employees' affective commitment and knowledge sharing behavior. Kang, Lee, and Kim [35] suggest that knowledge management user psychological empowerment and work environment including job autonomy increases knowledge management user empowerment.

In terms of knowledge sharing; knowledge management literature identified two types of knowledge sharing strategies including personalization and codification. Personalization strategy of knowledge sharing is based on direct and personal sharing of knowledge among employees, whereas codification knowledge sharing strategy uses databases for sharing knowledge [36-38]. Employees however, prefer to share knowledge interpersonally than using databases [29]. This study therefore, considers the personal aspect of knowledge sharing in order to identify the cognitive/behavioral factors related to individual's childhood experiences that motivate them to share more knowledge in their later life. 


\subsection{Childhood Development Theories}

Parent's behavior plays important role in the development of children behavior. There is abundant research available in child development literature that explains the role of parents in developing children's physical, cognitive, social and emotional behaviors. The work of four theorists namely; Erikson [39], Kohlberg [40], Piaget [41], and Bronfenbrenner [42], is important to explain the child's cognitive, moral and emotional development [43]. According to Piaget [41], young children use their sensory knowledge to think and learn about things they experience. According to Erikson [39], th withdrawal or engagement of young children in new activities depends upon the type of support and nurturing received from their parents. Kohlberg [40] extends the social development theory originally presented by Piaget (1932) and proposed a six stage model of moral development among children. This theory postulates that ethical behavior among children is based on moral reasoning. Kohlberg [40] believes that moral development is basically concerned with perceptions of justice and the process of moral development continues throughout one's lifetime.

Bronfenbrenner [42] presents bio-ecological theory which describes that child's mental growth and development depends upon their genetic and biologically influenced personality traits they borrow from their parents. Bronfenbrenner [42] holds that four systems including; microsystem (the innermost and the closest one containing parents, family, school, neighborhood, daycare is the most immediate and influential on child development), mesosystem (results from the interaction of microsystems e.g., parent-teacher, school playground, church service), exosystem (the interaction of micro and exosystem, having no direct impact on child development e.g., parents workplace schedule) and finally, macrosystem (the social blueprints that influence all lower systems e.g., cultural values, political upheavals, economic disruptions etc., that shape collective development). A fifth system was later added to Bronfenbrenner [42] bio-ecological model is time, that influences child's development for instance, parents illness or death which influences more on children with less age as compared to adults.

Another hallmark theory to explain children development is theory of mind (ToM) presented by Premack, and Woodruff [44] is the ability to impute ones' mental state (belief, desire, knowledge) with others. Theory of mind believes that human behaviors are developed during early childhood years and the emotional self-regulation is based on the feelings of others. The social learning theory by Bandura [45] is also instrumental in understanding child's development process. Bandura [45] holds that learn by observing and imitating their parents and other members in their social networks. Theory of applied behavior analysis (ABA) referred to as "the science devoted to the understanding and improvement of human behavior" ([46], p. 3). Theory of ABA postulates that individual's behaviors can be understood by observing the environmental factors related to learning and that a child's desirable behaviors can be shaped by parents through the process of re-enforcement ([47], p. 25).

Child rearing practices used by parents significantly influence children's social development $[48,49]$. Baumrind's [50] introduced three types of parenting practices including authoritarian, authoritative and permissive/training patenting styles. Authoritative parenting style is associated with showing high level of warmth and guidance behavior towards child rearing and encouraging children to express their opinion in order to promote their self-expression and confidence [48,51,52]. Whereas parents using authoritarian parenting practices do not allow child to question their decisions, show low warmth and guiding behavior with high control on children and hostile behavior [48,51-53]. Permissive parenting style believes that there should be minimum rules and standards of behaviors from parents and few interventions by parents to shape behaviors of their children $[48,50]$. Research shows that permissive parenting practice results in low self-regulations and self-esteem among children [54]. Chao [55] introduced training as another parenting style being practiced by parents in collectivist cultures. According to training parenting style, children are by nature born good and parents should encourage their children to achieve their performance goals [52]. The current study is using authoritative, authoritarian and training parenting styles to investigate their impact on the development of children altruistic and sharing behaviors. 
All the above theories explains that childhood experiences including parental child rearing practices and social factors influence children's personal development that form the basis of the behaviors in their later life.

\subsection{Hypotheses Development}

\subsubsection{Parent Educational Background and Children Altruistic Behavior}

Altruism is one of the core social values that parents teach to their children [56]. Parents encourage their children to share their toys and meals with other children in order to promote altruistic behavior among their children [56]. Many previous researches confirm positive the association between theory of mind and altruistic behavior among individuals. For instance, Devanath [57]; Takagishi, Kameshima, Schug, Koizumi, and Yamagishi [58]; and Wu and Su [59] believe that theory of mind is a cognitive component of altruistic behavior among children in their later life. The parental socio-economic factors and knowledge level helps children in developing their altruistic behavior. Numerous studies have examined the influence of parental education on the development of positive behaviors among children. For instance, Chevalier [60] holds that parental education has a positive and significant on children development and achievements. Benenson, Pascoe, and Radmore [61] suggest that children with higher parental socio-economic status exhibit higher level of altruistic behavior. Karmakar and Ghosh [62] also hold that parental education has significant impact in developing children altruistic behavior. Similarly, Bradley and Corwyn [63] found strong influence of parental socio-economic status including their education level on development of positive behaviors among children. Parents with higher education level enjoy better socio-economic status and knowledge seeking opportunities, therefore, current study assumes that children with higher parental knowledge and education level have more altruistic values as compared to those children whose parents have less knowledge and educational attainment. The current study therefore, assumes that higher level of parental education develop altruistic behavior among children that continues throughout their later life.

Hypothesis 1 (H1). Parent educational background has a significant positive influence on the development of altruistic behavior among children in their later.

\subsubsection{Parenting Practices and Children Altruistic Behavior}

Parenting practices play an important role in the development of social and altruistic behavior among children. Research suggests that sharing behavior among children is developed in their early childhood years, and it continues to be the same in their later life. For instance, Chernyak and Kushnir [28] hold that rearing children to sacrifice their toys with others as their own decision and not as forced choice, develop their inner willingness to share more in future. Many studies including; Baumrind's [50]; Chen, Dong, and Zhou [48]; and McGillicudy-DeLisi [49] hold that child rearing practices used by parents significantly influence development of social (altruistic) behavior among children. Particularly the 'permissive/training' parenting practice introduced by Chao [55] strongly encourages and motivates the children to display high levels of positive behaviors. According to training parenting style, children are by nature born good and parents should encourage their children to achieve their performance goals [52]. The children reared in parenting styles that encourage children to share their resources are likely to continue such altruistic behaviors throughout the course of their lives. The current study therefore, assumes that parenting practices largely determines the altruistic behavior among children that sustains during their later life.

Hypothesis 2 (H2). Parenting practices has a significant positive influence on children altruistic behavior. 


\subsubsection{Parental Socialization Goals and Children Altruistic Goals}

"Socialization is the process through which children learn the norms, values and the customs of their society, culture and family" [57]. Research on the antecedents of altruistic behavior shows socialization as major component in the development of altruistic behavior $[57,64,65]$. Through the process of socialization parents wants their children to learn cultural lessons and practices that will endure in their adulthood life $[57,66]$. Research also suggest that socialization is an important determinant of altruistic behavior among children. For instance, Eisenberg et al. [64]; Devanath [57]; and Piliavin and Charng [65] believe through socialization, children learn the sharing norms values from their culture, family and society. This argument is also supported by the social learning theory proposed by Bandura [45], which holds that children learn by observing and imitating their parents and other members in their social networks. The current study therefore, assumes that parental socialization goals are important childhood experiences that facilitate altruistic behavior among children in their later life.

Hypothesis 3 (H3). Parental socialization goals has a significant positive influence on children altruistic behavior.

\subsubsection{Altruistic Behavior and Knowledge Sharing Behavior}

Finally, the altruistic behavior developed among children during their childhood motivates them to share their knowledge resources with their colleagues in their organizations. Chernyak and Kushnir [28] believe that "Allowing children to make difficult choices may influence their sharing behavior by teaching them greater lessons about their abilities, preferences, and intentions towards others". The children who learn to share resource in their early childhood continue to share in their entire later life. Therefore, parents intentionally teach these values to their children through child-rearing practices [66]. Knowledge is also a resource; therefore, the current study assumes that the adults who have learned and developed sharing and altruistic behavior share more knowledge as compared to those individuals who have less altruistic values.

Hypothesis 4 (H4). Altruistic behavior among children has a significant positive influence on the development of knowledge sharing behaviors in their later life.

\subsection{The Research Framework of This Study}

The conceptual model of this study is presented in Figure 1. There was no previous research exploring the effects of childhood experiences in developing children altruistic behavior and the translation of this children altruistic behavior into knowledge sharing behavior. The independent variable in this model is children knowledge related experiences including: parental level of knowledge which can be measured by level of educational attainment by both parents. The second independent variable is parenting practices including authoritative, authoritarian and training, which can be measured by asking questions to respondents regarding practicing of child rearing strategy by their parents in their childhood. The third independent variable is parental socialization goals, which can be measured by asking the extent of socialization efforts of parents during respondents' child-rearing process. Knowledge sharing is dependent variable in this model. This study assumes that knowledge sharing can be increased by developing higher level of altruistic behavior among children. Whereas, altruistic behavior among children can be developed if parents have more knowledge, adopt appropriate child rearing practices and promote socialization among their children. 


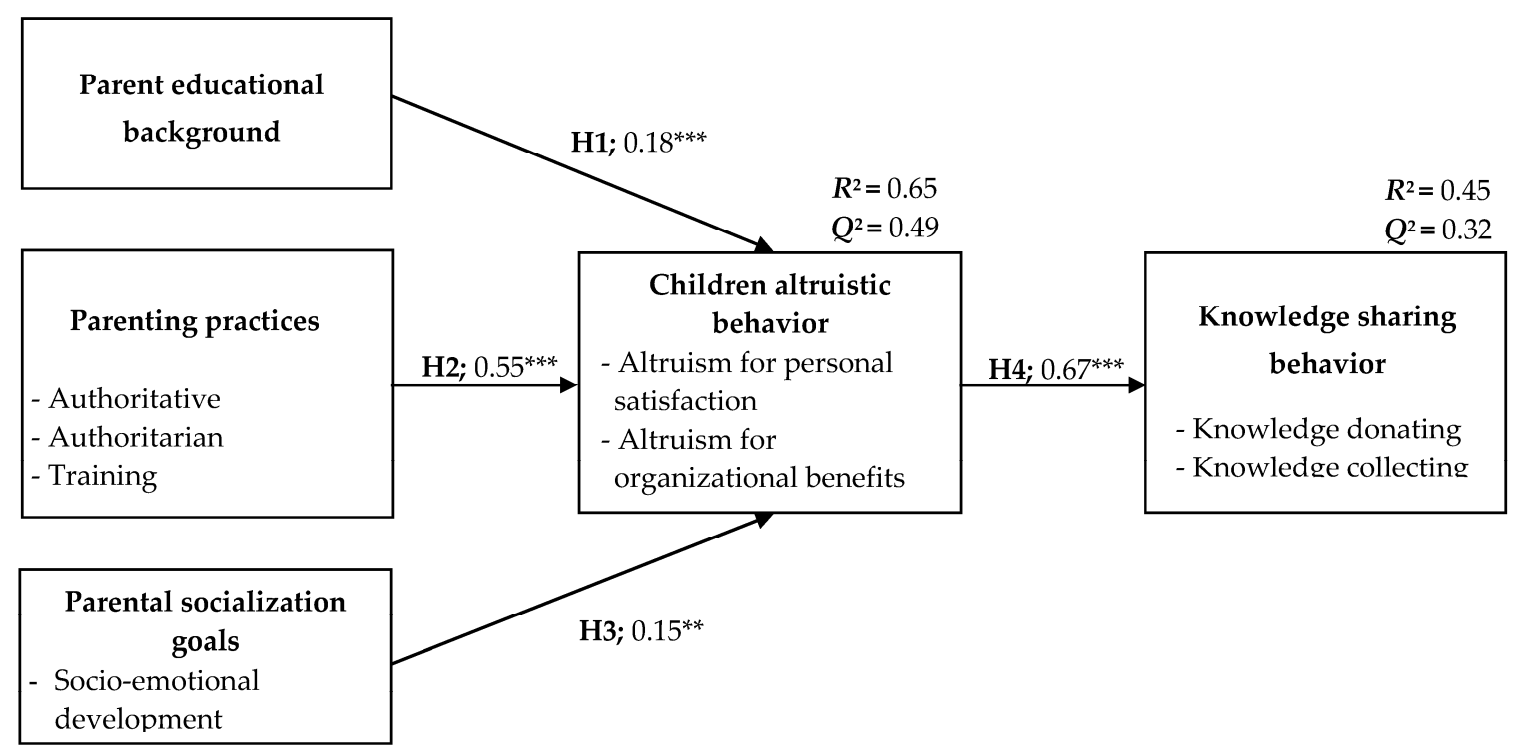

Figure 1. The conceptual model. Note: ${ }^{* *}|\mathbf{t}| \geq 2.33$ at $p 0.01$ level; ${ }^{* * *}|\mathbf{t}| \geq 3.09$ at $p 0.001$ level; $R^{2}=$ Determination coefficients; $Q^{2}=$ Predictive relevance of endogenous.

\section{Method}

\subsection{Data and Sample}

Data are collected through an online administration of survey in Pakistan. Personal and professional contacts of the authors provided access to the online sites. Invitations to the survey included a cover letter that indicated that participation was voluntary. Respondents are also assured that their individual responses would remain confidential. The fieldwork yields a total of 310 complete and valid responses. According to statistical power analysis using G*Power 3.1.9.2 program [67], the model used in this study requires a sample size of 174 to detect $R^{2}$ values of around 0.25 , therefore, the statistical power of the sample of 310 observations is acceptable, assuming significance level of $5 \%$, a statistical power of $99 \%, 3$ constructs of this study (the most complex regression in our model), 61 items, and an effect size of 0.15 [68]. However, the minimum acceptable power required in social science and behavior science research is typically $80 \%$. Therefore, we can safely conclude that the sample size of 310 is acceptable for the purpose of this study. Since the respondents were fluent in English and that past research has effectively employed English questionnaires in Pakistan [69-71], the questionnaires are not translated in Urdu. Using universal measures in English also provides a better opportunity to compare the findings of this study with those of past research that used English measures (i.e., primarily conducted in the West; Naseer et al. [72]). Each participant completed a survey that contained items related to parenting practices, parenting socialization goals, children altruistic behavior and knowledge sharing behavior. In addition, each participant also provided his or her demographic details such as gender, age, year of education, currently employed or not, year of work experience as well as parents educational background. The demographic characteristics of the respondents are given in Table 1.

Table 1. Demographic characteristics of the sample.

\begin{tabular}{llcc}
\hline \multicolumn{2}{c}{ Demographic Characteristics } & Numbers & Percent (\%) \\
\hline Gender & & 198 & 63.87 \\
& Male & 112 & 36.13 \\
\hline
\end{tabular}


Table 1. Cont.

\begin{tabular}{|c|c|c|}
\hline Demographic Characteristics & Numbers & Percent $(\%)$ \\
\hline \multicolumn{3}{|l|}{ Respondent's age } \\
\hline Less than 20 years & 19 & 6.1 \\
\hline $21-30$ years & 158 & 51.0 \\
\hline $31-40$ years & 126 & 40.6 \\
\hline $41-50$ years & 7 & 2.3 \\
\hline 51 to 60 years & 0 & 0.0 \\
\hline More than 61 years & 0 & 0.0 \\
\hline \multicolumn{3}{|l|}{ Respondent's education } \\
\hline Less than Matriculation & 0 & 0.0 \\
\hline Intermediate & 4 & 1.3 \\
\hline Undergraduate (Bachelors) & 62 & 20.0 \\
\hline Postgraduate (Masters) & 195 & 74.8 \\
\hline Postgraduate $(\mathrm{PhD})$ & 12 & 3.9 \\
\hline \multicolumn{3}{|l|}{ Currently employed } \\
\hline Yes & 242 & 78.1 \\
\hline No & 68 & 21.9 \\
\hline \multicolumn{3}{|l|}{ Respondent's work experience } \\
\hline Less than 1 year & 66 & 21.3 \\
\hline $2-5$ years & 88 & 28.4 \\
\hline $5-10$ years & 78 & 25.2 \\
\hline $11-15$ years & 52 & 16.8 \\
\hline More than 16 years & 26 & 8.4 \\
\hline \multicolumn{3}{|c|}{ Respondent's father educational background } \\
\hline Never went to school & 10 & 3.2 \\
\hline Less than Marticulation & 15 & 4.8 \\
\hline Undergraduate (Bachelors) & 142 & 45.8 \\
\hline Postgraduate (Masters) & 138 & 44.5 \\
\hline Postgraduate (PhD) & 5 & 1.6 \\
\hline \multicolumn{3}{|c|}{ Respondent's mother educational background } \\
\hline Never went to school & 7 & 2.3 \\
\hline Less than Marticulation & 19 & 6.1 \\
\hline Undergraduate (Bachelors) & 100 & 32.3 \\
\hline Postgraduate (Masters) & 149 & 58.4 \\
\hline Postgraduate (PhD) & 3 & 0.1 \\
\hline
\end{tabular}

\subsection{Measures}

The measurement scales used in this research are based on the literature review in Section 2. The instruments for measuring different behavioral constructs [73] used in this study including; childhood experiences (parental education, parenting practices and parent socialization goals), children altruistic behaviors and knowledge sharing behavior have been adopted from well-recognized and well-published studies. Parental educational level is measured through the academic qualification of both parents and is formed as a unidimensional first-order reflective construct with two items. The parental socialization goals construct is measured through a scale adopted from Pearson and Rao [52] and is formed as a unidimensional first-order reflective construct with fifteen items. The current study used only socio-emotional development dimension of socialization goals, the other two dimensions (academic achievements and filial piety) have not been considered in this study. Pearson and Rao [52] used the work of Chen et al. [48] and Rubin and Mills [74], for the development of socio-emotional development scale.

The study used modified version of parenting practices scale developed by Pearson and Rao [52]. The parenting practices scale is formed as a second-order reflective construct (Mode A) with three first-order reflective constructs that are, authoritarian (seven items), authoritative (eleven items), 
and training (twelve items). The instrument to measure children altruistic behavior is adopted from Chiu, Hsu, and Wang. [75], Lin [25], and Wang and Hou [76] and is formed as a second-order reflective construct with two first-order constructs that are altruism for personal satisfaction, and altruism for organizational benefits. The study used scales for measuring both dimensions of altruism from Wang and Hou [76]. There are three items in altruism for personal satisfaction scale, and Wang and Hou [76] used the work of Lin [25] for the development of this scale. Altruism for organizational benefit scale also contains three items and the work of Chiu et al. [75] has been used by Wang and Hou [76] for the development of this scale. Knowledge sharing behavior is formed as a second-order reflective construct and has been measured by using two first-order reflective constructs i.e., knowledge donating and knowledge collecting. There are different scales available in the literature to measure knowledge sharing, since donating is more close to altruistic behavior, the current study has used this scale. The knowledge donating and knowledge collecting scales have been developed by van den Hooff and Hendrix [77], both are first-order reflective constructs contain four items. Following the recent recommendations in Henseler [73], Rigdon, Sarstedt, and Ringle [78], Sarstedt, Hair, Ringle, Thiele, and Gudergan [79], and van Riel, Henseler, Kemény, and Sasovova [80], all constructs are estimated in Mode A, at the item, the first-order and the second-order construct level. Finally, this study follows Wright, Campbell, Thatcher, and Roberts [81] to use the two-stage approach to evaluate the all hierarchical second-order constructs [82]. In the first stage model, the latent variables of all the first-order constructs are estimated without the hierarchical second-order construct present. In the second stage model, the latent variables of all these first-order constructs served as manifest variables for the hierarchical second-order constructs in a separate second-stage analysis [82].

The items for all constructs have been measured on 5 point Likert scale ranging from 1 for strongly disagree to 5 for strongly agree. The sample items is given in Appendix A.

\subsection{Data Analysis and Results}

Structural equation modeling (SEM) is commonly consist of two types, i.e., covariance-based SEM (CB-SEM) and variance-based SEM or partial least squares SEM (PLS-SEM; also called PLS path modeling). CB-SEM is one of the maximum-likelihood modeling or factor-based techniques (e.g., LISREL, AMOS, EQS, and Mplus etc.), relies on the overall fit of the proposed model by goodness-of-fit tests, and is suitable for confirmatory studies. PLS-SEM is one of the multiple linear regression modeling techniques (e.g., SmartPLS, WarpPLS, PLS-Graph, and ADANCO), relies on the maximization of the explained variance of the dependent variables, and is suitable for exploratory studies [83].

This study employs PLS-SEM [84-87] or more specifically, SmartPLS 3 [88] to estimate the measurement and structural model. PLS-SEM has its distinct features compared to CB-SEM. For instance, PLS-SEM does not have minimal requirements of the restrictive assumptions such as measurement scales, sample size, and distributional assumptions imposed by CB-SEM [83]. This study considers PLS-SEM instead of CB-SEM as a more suitable technique for the following reasons: (1) this study focuses on prediction and explaining the variance in key target constructs (e.g., children altruistic behavior and knowledge sharing behavior) [89-91]; (2) the research model shows a complex structure-contains four series of direct relationship and level of multi-dimensionality (first- and second-order composite constructs) [86,89,90]; (3) the relationship among parent educational background, parenting practices, parental socialization goals, children altruistic behavior and knowledge sharing behavior is believed to be in early stage of theory development and thus creates the opportunity where new phenomena are to be explored [86]; (4) using of latent variables scores in the subsequent analysis of predictive relevance, particularly in the implementation of the two-stage approach for modeling the multi-dimensionality of parenting practices, children altruistic behavior and knowledge sharing behavior $[86,89,91]$ and finally this study adopts the advantage of PLS-SEM in terms of less rigorous requirement of restrictive assumption as it enables researchers to create and estimate such models without imposing additional limiting constraints [90]. 


\section{Results}

The psychometric properties of reliability, validity and dimensionality of each construct were assessed prior to undertaking hypothesis testing via exploratory factor analysis (EFA), by assessing the reliabilities, average variance extracted (AVE), square root of the average variance extracted, and interconstruct correlations.

\subsection{Evaluation of Measurement Model}

This study operationalizes the parenting practices as a single construct made up of three first order dimensions: authoritarian, authoritative and training. As appears in Table 2, the three dimensions reflect the higher-order construct. Similarly, this study measures children altruistic behavior as a second-order construct consisting of two first order dimensions: altruism for personal satisfaction and altruism for organizational benefits. While knowledge sharing behavior is formed as a second-order construct consisting of knowledge collecting and knowledge donating as first order constructs. Finally, parent educational background and socio-emotional development are formed as first order constructs.

Table 2. Measurement model results.

\begin{tabular}{|c|c|c|c|c|c|c|}
\hline \multicolumn{7}{|c|}{ Step I: Results of the Assessment of Measurement Model for First-Order Constructs } \\
\hline First-order Compiste Mode A & SFL & SE & $t$-Value & CR & $\alpha$ & AVE \\
\hline \multicolumn{4}{|c|}{ Parent educational background (first-order composite Mode A) } & 0.81 & 0.60 & 0.68 \\
\hline FEDU & 0.78 & 0.05 & 16.70 & & & \\
\hline MEDU & 0.87 & 0.03 & 31.92 & & & \\
\hline \multicolumn{4}{|c|}{ Authoritarian (first-order composite Mode A) } & 0.91 & 0.89 & 0.61 \\
\hline AURIAN1 & 0.71 & 0.04 & 19.94 & & & \\
\hline AURIAN2 & 0.70 & 0.03 & 21.23 & & & \\
\hline AURIAN3 & 0.79 & 0.03 & 31.05 & & & \\
\hline AURIAN4 & 0.84 & 0.02 & 43.27 & & & \\
\hline AURIAN5 & 0.80 & 0.02 & 32.91 & & & \\
\hline AURIAN6 & 0.78 & 0.03 & 25.51 & & & \\
\hline AURIAN7 & 0.81 & 0.02 & 32.56 & & & \\
\hline \multicolumn{4}{|c|}{ Authoritative (first-order composite Mode A) } & 0.91 & 0.89 & 0.50 \\
\hline AUTIVE1 & 0.55 & 0.04 & 13.01 & & & \\
\hline AUTIVE2 & 0.68 & 0.03 & 20.23 & & & \\
\hline AUTIVE3 & 0.60 & 0.06 & 10.33 & & & \\
\hline AUTIVE4 & 0.52 & 0.06 & 8.85 & & & \\
\hline AUTIVE5 & 0.60 & 0.06 & 10.57 & & & \\
\hline AUTIVE6 & 0.62 & 0.05 & 13.60 & & & \\
\hline AUTIVE7 & 0.76 & 0.03 & 23.88 & & & \\
\hline AUTIVE8 & 0.78 & 0.03 & 27.94 & & & \\
\hline AUTIVE9 & 0.79 & 0.03 & 30.00 & & & \\
\hline AUTIVE10 & 0.83 & 0.02 & 34.83 & & & \\
\hline AUTIVE11 & 0.81 & 0.02 & 34.93 & & & \\
\hline \multicolumn{4}{|c|}{ Training (first-order composite Mode A) } & 0.93 & 0.92 & 0.54 \\
\hline TRG1 & 0.74 & 0.03 & 23.11 & & & \\
\hline TRG2 & 0.75 & 0.03 & 25.09 & & & \\
\hline TRG3 & 0.78 & 0.03 & 30.78 & & & \\
\hline TRG4 & 0.77 & 0.03 & 30.70 & & & \\
\hline TRG5 & 0.73 & 0.04 & 20.07 & & & \\
\hline TRG6 & 0.77 & 0.03 & 26.86 & & & \\
\hline TRG7 & 0.81 & 0.02 & 34.58 & & & \\
\hline TRG8 & 0.79 & 0.03 & 30.95 & & & \\
\hline TRG9 & 0.77 & 0.03 & 27.98 & & & \\
\hline TRG10 & 0.60 & 0.04 & 13.66 & & & \\
\hline TRG11 & 0.70 & 0.03 & 20.10 & & & \\
\hline TRG12 & 0.60 & 0.05 & 12.22 & & & \\
\hline
\end{tabular}


Table 2. Cont.

\begin{tabular}{|c|c|c|c|c|c|c|}
\hline \multicolumn{7}{|c|}{ Step I: Results of the Assessment of Measurement Model for First-Order Constructs } \\
\hline First-order Compiste Mode A & SFL & SE & $t$-Value & CR & $\alpha$ & AVE \\
\hline \multicolumn{4}{|c|}{$\begin{array}{l}\text { Parental socialization goals Socio-emotional } \\
\text { development (first-order composite Mode A) }\end{array}$} & 0.93 & 0.92 & 0.50 \\
\hline SED1 & 0.55 & 0.05 & 11.26 & & & \\
\hline SED2 & 0.70 & 0.03 & 22.24 & & & \\
\hline SED3 & 0.75 & 0.03 & 25.73 & & & \\
\hline SED4 & 0.76 & 0.03 & 27.62 & & & \\
\hline SED5 & 0.76 & 0.03 & 28.83 & & & \\
\hline SED6 & 0.73 & 0.03 & 23.51 & & & \\
\hline SED7 & 0.57 & 0.05 & 10.51 & & & \\
\hline SED8 & 0.69 & 0.03 & 20.55 & & & \\
\hline SED9 & 0.57 & 0.06 & 10.45 & & & \\
\hline SED10 & 0.70 & 0.04 & 19.31 & & & \\
\hline SED11 & 0.69 & 0.04 & 18.33 & & & \\
\hline SED12 & 0.75 & 0.03 & 25.76 & & & \\
\hline SED13 & 0.72 & 0.03 & 21.13 & & & \\
\hline SED14 & 0.72 & 0.03 & 21.61 & & & \\
\hline SED15 & 0.67 & 0.04 & 18.01 & & & \\
\hline \multicolumn{4}{|c|}{ Altruism for personal satisfaction (first-order composite Mode A) } & 0.88 & 0.80 & 0.72 \\
\hline APS1 & 0.87 & 0.02 & 50.52 & & & \\
\hline APS2 & 0.79 & 0.02 & 33.97 & & & \\
\hline APS3 & 0.87 & 0.02 & 49.92 & & & \\
\hline \multicolumn{4}{|c|}{ Altruism for organizational benefits (first-order composite Mode A) } & 0.92 & 0.88 & 0.80 \\
\hline AOB1 & 0.89 & 0.01 & 79.78 & & & \\
\hline AOB2 & 0.93 & 0.01 & 96.50 & & & \\
\hline AOB3 & 0.86 & 0.02 & 42.07 & & & \\
\hline \multicolumn{4}{|c|}{ Knowledge collecting (first-order composite Mode A) } & 0.93 & 0.90 & 0.77 \\
\hline KC1 & 0.88 & 0.01 & 58.99 & & & \\
\hline KC2 & 0.88 & 0.02 & 49.00 & & & \\
\hline KC3 & 0.91 & 0.01 & 72.44 & & & \\
\hline KC4 & 0.85 & 0.02 & 35.01 & & & \\
\hline \multicolumn{4}{|c|}{ Knowledge donating (first-order composite Mode A) } & 0.84 & 0.75 & 0.57 \\
\hline KD1 & 0.71 & 0.05 & 13.79 & & & \\
\hline KD2 & 0.75 & 0.05 & 16.42 & & & \\
\hline KD3 & 0.76 & 0.03 & 26.14 & & & \\
\hline KD4 & 0.80 & 0.03 & 30.54 & & & \\
\hline
\end{tabular}

Step II: Results of the assessment of measurement model after generating second-order constructs

\begin{tabular}{|c|c|c|c|c|c|c|}
\hline Second-order compite Mode A & CW & SE & $t$-Value & CR & $\alpha$ & AVE \\
\hline \multicolumn{4}{|c|}{ Parenting practices (second-order composite Mode A) } & 0.92 & 0.86 & 0.78 \\
\hline Authoritarian & 0.89 & 0.01 & 63.26 & & & \\
\hline Authoritative & 0.90 & 0.02 & 50.00 & & & \\
\hline Training & 0.87 & 0.02 & 48.98 & & & \\
\hline \multicolumn{4}{|c|}{ Children altruistic behavior (second-order composite Mode A) } & 0.91 & 0.81 & 0.84 \\
\hline Altruism for personal satisfaction & 0.92 & 0.01 & 97.08 & & & \\
\hline Altruism for org. benefits & 0.91 & 0.01 & 66.11 & & & \\
\hline \multicolumn{4}{|c|}{ Knowledge sharing behavior (second-order composite Mode A) } & 0.84 & 0.63 & 0.72 \\
\hline Knowledge collecting & 0.78 & 0.04 & 19.03 & & & \\
\hline Knowledge donating & 0.91 & 0.01 & 76.80 & & & \\
\hline
\end{tabular}

Note: $\mathrm{SFL}=$ Standardised factor loading; $\mathrm{SE}=$ Standard error; $\mathrm{CR}=$ Composite reliability; $\alpha$ = Cronbach's alpha; $\mathrm{AVE}=$ average variance extracted; $\mathrm{CW}=$ Correlational weights of first-order compoiste on second-order composite. 


\subsubsection{Reliability}

The assessment of the individual reliability of the items depends on examining the standardized factor loadings. A popular rule of thumb is to accept items with loadings of 0.707 [92]. In Table 2 the standardized factor loadings for all first order constructs of each measurement item are provided. The $t$-test of all the loadings is at the $p<0.001$ level. All the loadings are above this minimum value.

The reliability and convergent validity of the constructs is evaluated by analyzing the Cronbach's alpha and composite reliability of the indicator. Nunnally [93] recommends a value of 0.70 (in exploratory research, 0.60 to 0.70 is considered acceptable) as a threshold value for this indicator. The Cronbach's alpha scores ranged between 0.60 and 0.92 while the composite reliability scores ranged between 0.81 and 0.93 , indicating adequate convergence or internal consistency. Table 3 shows the means, standard deviation, correlation for all the constructs and the square root of the AVE on the diagonals. Mean values depict that most constructs are generally above their respective mid-point, while correlations among the independent constructs are relatively low. Thus, multi-collinearity was not a concern in this study [94].

\subsubsection{Validity}

The average variance extracted (AVE) provides an assessment of convergent validity. Fornell and Larcker [92] recommend an AVE value $\geq 0.50$. This means that $50 \%$ or more of the indicator variance should be accounted for. Consistent with this suggestion, all the constructs have an AVE value above this minimum threshold as shown in Table 2.

This study assesses the discriminant validity by three commonly used approaches, i.e., (1) Fornell-Larcker criterion; (2) cross-loadings analysis; and (3) Heterotrait-Monotrait (HTMT) ratio. The correlation matrix in Table 3 shows that for each pair of constructs, the AVE square root of each construct is higher than the absolute value of their correlation [92]. The results of cross-loadings show that all items loaded higher on their respective constructs than on the other constructs and the cross-loadings differences are much higher than the suggested threshold of 0.10 [95]. Finally, the results of the HTMT ratio as shown in Table 3 confirm that values of the HTMT are below the threshold of 0.85 or 0.90 [96].

\subsubsection{Assessing of Hierarchical Second-Order Constructs}

As this study assessed hierarachical second-order composites (Mode A) by using the two-stage approach. Table 2 shows the correlation weights [97] of first-order composite (Mode A). Results of the assessment of measurement model after generating second-order composites (Mode A) in Table 2 shows that the correlational weights of first-order composites on second-order composite-parenting practices have a positive weight ( 0.89 authoritarian, 0.90 authoritative, and 0.87 training). Similarly, the correlational weights of first-order composites that are, altruism for personal satisfaction (0.92), and altruism for organizational benefits (0.91) have a positive weight on second-order composite-children altruistic behavior. Finally, the correlational weights of first-order composites that are knowledge collecting (0.78), and knowledge donating (0.91) have a positive weight on second-order composite-knowledge sharing behavior. All weights are significant at the 0.001 . 
Table 3. Mean, standard deviations, correlations and discriminant validity results.

\begin{tabular}{|c|c|c|c|c|c|c|c|c|c|c|c|}
\hline & Mean & SD & 1 & 2 & 3 & 4 & 5 & 6 & 7 & 8 & 9 \\
\hline $\begin{array}{l}\text { 1. Parent educational background } \\
\text { Parenting practices }\end{array}$ & 3.55 & 0.71 & 0.82 & 0.75 & 0.83 & 0.75 & 0.84 & 0.82 & 0.78 & 0.69 & 0.79 \\
\hline 2. Authoritarian & 3.18 & 0.81 & $0.45^{* *}$ & 0.79 & 0.71 & 0.75 & 0.64 & 0.78 & 0.45 & 0.50 & 0.79 \\
\hline 3. Authoritative & 3.29 & 0.78 & $0.48^{* *}$ & $0.63^{* *}$ & 0.70 & 0.71 & 0.79 & 0.66 & 0.82 & 0.59 & 0.82 \\
\hline $\begin{array}{l}\text { 4. Training } \\
\text { Parental socialization goals }\end{array}$ & 3.38 & 0.80 & $0.43^{* *}$ & $0.58^{* *}$ & $0.53^{* *}$ & 0.74 & 0.78 & 0.67 & 0.76 & 0.48 & 0.76 \\
\hline $\begin{array}{l}\text { 5. Socio-emotional development } \\
\text { Children altruistic behavior }\end{array}$ & 3.24 & 0.80 & $0.46^{* *}$ & $0.59^{* *}$ & $0.71^{* *}$ & 0.63 ** & 0.69 & 0.69 & 0.79 & 0.60 & 0.84 \\
\hline $\begin{array}{l}\text { 7. Altruism for organizational benefits } \\
\text { Knowledge sharing behavior }\end{array}$ & 3.55 & 0.79 & $0.52 * *$ & $0.59^{* *}$ & $0.58^{* *}$ & $0.58^{* *}$ & $0.62^{* *}$ & $0.684^{* *}$ & 0.89 & 0.47 & 0.80 \\
\hline 8. Knowledge Collecting & 3.43 & 0.77 & $0.49^{* *}$ & $0.69^{* *}$ & $0.61^{* *}$ & $0.55^{* *}$ & $0.62 * *$ & $0.59 * *$ & $0.56^{* *}$ & 0.88 & 0.55 \\
\hline 9. Knowledge Donating & 3.48 & 0.95 & $0.35^{* *}$ & $0.33 * *$ & $0.42 * *$ & $0.42 * *$ & $0.44^{* *}$ & $0.43 * *$ & $0.36^{* *}$ & $0.38^{* *}$ & 0.75 \\
\hline
\end{tabular}

Note: ${ }^{* *}|\mathrm{t}| \geq 2.33$ at $p 0.01$ level; SD = Standard deviation; Diagonal and italicized elements are the square roots of the AVE (average variance extracted). Below the diagonal elements are the correlations between the constructs values. Above the diagonal elements are the HTMT values. 


\subsection{Evaluation of Structural Model}

The PLS-SEM technique does not use the conventional goodness of-fit measures [98]. This study follows Hair et al. [68] to estimate the structural model. The collinearity among the constructs in the structural model is assessed. The only result for assessing collinearity issues is the variance inflation factor (VIF) value. This study assesses two sets of (predictors) constructs for collinearity. The VIF are calculated using the SPSS program (version 22.0) to examine multi-collinearity. The results show minimal collinearity in the structural model as all VIF values are far below the common cutoff threshold of 5 to 10 [68].

Next, the structural model predictability is computed by means of variance explained $R^{2}$ values for the dependent latent constructs. $R^{2}$ may vary depend upon the research area. Chin [89] suggests values of $0.67,0.33$, and 0.19 as measure of $R^{2}$ to be considered substantial, moderate, and weak respectively. The $R^{2}$ (Children altruistic behavior) $=0.65$, and $R_{\text {(Knowledge sharing behavior) }}^{2}=0.45$; therefore, these values are considered moderate and acceptable.

Furthermore, the sizes and significance of the path coefficients that represent the derived hypotheses were examined. Following Hair et al. [68], the significance levels of the path coefficients are obtained using the bootstrapping procedure (with a number of 5000 bootstrap samples and 310 bootstrap cases; using no sign changes). Table 4 provides the path coefficients, $t$-statistics, significance level, $p$-values as well as the accompanying bootstrap confidence intervals at 95 percent. An analysis of path coefficients and levels of significance show that all direct effects are significant. This study uses one-tailed and corresponding $p$-values for statistical inferences as following the guidelines suggested by Roldán and Sánchez-Franco [91]. Kock ([99], p. 1): suggests that "A one-tailed test is recommended if the coefficient is assumed to have a sign (positive or negative), which should be reflected in the hypothesis that refers to the corresponding association. If no assumptions are made about coefficient sign, a two-tailed test is recommended."

Table 4. Structural model results.

\begin{tabular}{|c|c|c|c|c|c|c|}
\hline \multirow{2}{*}{ Structural Path } & \multicolumn{2}{|c|}{ Hypotheses } & \multirow{2}{*}{$\begin{array}{c}\text { Path } \\
\text { Coefficient }\end{array}$} & \multirow{2}{*}{$\begin{array}{c}t \text {-Value } \\
\text { (Bootstrap) }\end{array}$} & \multirow{2}{*}{$\begin{array}{l}95 \% \text { BCa } \\
\text { Confidence } \\
\text { Interval } \\
\end{array}$} & \multirow{2}{*}{$f^{2}$ Value } \\
\hline & Number & Sign & & & & \\
\hline $\begin{array}{l}\text { Parent educational background } \rightarrow \\
\text { Children altruistic behavior }\end{array}$ & $\mathrm{H} 1$ & + & $0.18^{* * *}$ & 3.77 & $(0.09,0.28)$ & 0.11 \\
\hline $\begin{array}{l}\text { Parenting practices } \rightarrow \\
\text { Children altruistic behavior }\end{array}$ & $\mathrm{H} 2$ & + & $0.56^{* * *}$ & 8.29 & $(0.42,0.68)$ & 0.24 \\
\hline $\begin{array}{l}\text { Parental socialization goals } \rightarrow \\
\text { Children altruistic behavior }\end{array}$ & $\mathrm{H} 3$ & + & $0.15^{* *}$ & 2.14 & $(0.01,0.29)$ & 0.09 \\
\hline $\begin{array}{l}\text { Children altruistic behavior } \rightarrow \\
\text { Knowledge sharing behavior }\end{array}$ & $\mathrm{H} 4$ & + & $0.67^{* * *}$ & 17.71 & $(0.59,0.74)$ & 0.80 \\
\hline \multicolumn{7}{|c|}{$\begin{array}{l}\text { SRMR composite model }=0.063 \\
R^{2} \text { (Children altruistic behavior) }=0.65 ; Q^{2}(\text { Children altruistic behavior })=0.49 \\
\left.R_{(\text {Knowledge sharing behavior })}^{2}=0.45 ; Q^{2} \text { (Knowledge Sharing Behavior }\right)=0.32\end{array}$} \\
\hline
\end{tabular}

A path coefficient provides a first impression of the size of effect but it is not helpful in comparing the size of effect across the model, because a path coefficient is influenced by many other explanatory constructs [73]. Therefore, as a remedy Cohen [100] suggests to calculate the value of effect size $\left(f^{2}\right)$. An effect size $\left(f^{2}\right)$ is a measured used to assess the relative impact of an explanatory construct on a dependent construct [68]. $f^{2}$ of $0.02,0.15$, and 0.35 indicate small, medium and large effects [100]. 
Table 4 summarizes the results of the $f^{2}$ effect sizes with respect to all the relationships in the structural model.

Similarly, the blindfolding procedure produces the $Q^{2}$ values, which applies a sample re-use technique that omits part of the data matrix and uses the model estimates to predict the omitted part. For PLS-SEM models, a $Q^{2}$ value larger than zero in the cross-validated redundancy report indicates predictive relevance. Table 4 provides the $Q^{2}$ values of all the dependent constructs. All $Q^{2}$ values are considerably above zero, thus providing support for the model's predictive relevance in terms of out-of-sample prediction [90].

\subsubsection{Model Fit}

This study also calculates the overall model fit through standardized root-mean square residual (SRMR) as the root mean square discrepancy between the observed correlation and the model implied correlations. This study follows Henseler et al. [101] and refers to the standardized root mean square residual (SRMR) as an index for model validation. Scholars generally consider values below 0.08 as favorable [102] in this instance. While the model estimation with PLS-SEM reveals a SRMR value of 0.063 , which confirms the overall fit of PLS path model $[68,96]$.

\subsubsection{Predictive Validity}

The value of $R^{2}$ shows how well the proposed structural model explain endogenous construct while value of $Q^{2}$ shows adequacy of predictive relevance of structural model. Yet, structure model is not indicative of how exogenous constructs predict endogenous construct (outcome of interest). A fit is not always a good way of evaluating predictive validity [103]. Therefore, recently Shmueli, Ray, Estrada, and Chatla [104] suggesting to consider predictive validity and performance of PLS models. Predictive validity (out-of-sample prediction) refers to the ability of a model in the predication of output value with different data sample [105]. In line with previous research [106-110], this study evaluates the predictive validity through cross-validations tests with holdout samples. Particularly, this study follows the approach suggested by Cepeda-Carrión et al. [111] by dividing the original sample ( $n=310)$ randomly into two subsamples, i.e., a training sample (two-thirds of the sample, $n=207$ ) and a holdout sample (the remaining sample, $n=103$ ). Second, the training sample is used to estimate the parameters in the structural model (weights and path coefficients). Third, using the holdout sample, each sample case is standardized. Fourth, the construct scores for the holdout sample are formed as linear combinations of the respective sample using the weights obtained from the training sample. Fifth, the construct scores for the holdout sample are standardized. Sixth, for the two endogenous constructs (in the structural model using holdout sample), the predictive scores are created by using the path coefficients obtained from the training sample. Finally, for the two endogenous constructs, the correlation between their predictive scores and construct scores (children altruistic behavior, $r=0.70$, $p<0.01$; and knowledge sharing behavior, $r=0.51, p<0.01$ ) suggesting that the structural model in this study has acceptable predictive validity.

\section{Discussion and Conclusions}

Despite the literature suggesting a positive relationship among parent educational background, parenting practices, parental socialization goals, children altruistic behavior and knowledge sharing behavior, to date little research analyzes these relationships empirically in a single model. This study contributes to the literature by being the first to examine such relationships.

The findings of this study provide additional evidence to previous literature that altruistic behavior developed among individuals during their childhood has a positive effect on knowledge sharing behavior in their later professional life. Also, the findings show a positive relationship between educational background and children altruistic behavior, parenting practices and children altruistic behavior and parental socialization goals and children altruistic behavior. The findings of this study are supported by numerous previous researches. For instance, Karmakar and Ghosh [62] propose that 
parental education has significant impact in developing children altruistic behavior. Baumrind's [50]; Chen et al. [48]; and McGillicudy-DeLisi, [49] holds that child rearing practices used by parents significantly influence development of social (altruistic) behavior among children. Benenson, Pascoe, and Radmore [61] suggests that children with higher parental socio-economic status exhibit higher level of altruistic behavior. Similarly, Bradley and Corwyn [63] found strong influence of parental socio-economic status including their education level on development of positive behaviors among children. Likewise, Devanath [57], Eisenberg et al. [64], and Piliavin and Charng [65] believes that through socialization, children learn the sharing norms and values from their culture, family and society. The current study extends that individual practice these sharing values by sharing their knowledge for the betterment of their co-workers and the organizations they are associated with.

The study intends to review the childhood development theories including; psychological, cognitive, behavioral and social learning theories in shaping the altruistic behavior among children as an important determinant of knowledge sharing behavior in their later life. A conceptual model is developed after review of early childhood development and knowledge management literature. The integrative model proposes that the underlying early childhood cognitive factors are inevitable and integral for the development of altruistic behavior among children which leads to knowledge sharing behavior in their later life. This study concludes that the parents who rear their children in the environment of sacrificing for the wellbeing of others develop altruistic behavior among children. Altruistic behavior cannot be imposed in children's personality rather it can only be infused by exhibition of altruistic and self-others socialization goals behaviors by parents to develop such attributes among their children. Furthermore, the children reared in the altruistic environment display higher level of knowledge sharing behavior later in their professional life at the workplace.

The findings of this study provides important implications for multiple stakeholders including parents, organizational managers and researchers in childhood development and knowledge sharing behavior, knowledge management practitioners and managers. The study recommends parents to rear their children in high altruistic environment by practicing these values by themselves and by acting as 'role model' for their children. The children should be allowed to choose to sacrifice by themselves and not be forced, otherwise, it can backfire. The parents should realize that organization appreciate knowledge sharing behavior among their employees and the performance appraisal and other organizational rewards are based on employees' knowledge-based activities in the organizations. The knowledge management practitioners can ensure the possession of altruistic values among potential employees during selection of candidates, the candidates with high level of altruistic behavior are likely to exhibit more knowledge sharing behavior. Training sessions should also be arranged within the organizations to promote altruistic values among employees in order to motivate them to share knowledge.

\section{Limitations and Future Lines of Research}

As with any empirical study, this study has also limitations that offer avenues for further research. Firstly, though the results presented in this study confirm majority of the results, the study is to some degree exploratory. The future researchers can validate the research model in this study by collecting data from employees working in knowledge-based industries in different cultures. The influence of different parenting styles can also be examined in detail, in order to see when parenting style is more effective in developing higher level of altruistic values among children. The role of other behavioral/cognitive factors can also be examined to explain the knowledge sharing behavior in future researches. Some other mediating or moderating variables can be introduced to better explain this model in future studies. Future studies can also examine how various parenting practices can differ in shaping the altruistic behavior among children in their later life. The data are cross-sectional in nature rather than longitudinal which does not enable us to interpret the time sequence of the relationships among the main research variables. The interpretations of causality among the research variables should be exercised with cautioned. Therefore, it is suggested that longitudinal research 
would provide additional insights into probable causations to establish the underlying relationships more firmly. Finally, the survey data for the study were collected from the same source, using the same method, also may suffer bias.

Author Contributions: Imran Ali designed the research, collected the data and drafted the manuscript. Murad Ali mainly worked on PLS-SEM, interpretation of results, analysis along with suggestions for the overall structure, and drafted the manuscript. Saeed Baghish, and Thamer Ahmad S. Baazeem provided many good research advices and revised the manuscript. The sequence of authors reflects their respective contribution to the article. All the authors wrote, read and approved the final manuscript.

Conflicts of Interest: The authors declare no conflict of interest.

\section{Appendix A. Questionnaire Items Used}

Questionnaire items (5-point Likert scale: 1 "strongly disagree"; 5 "strongly agree")

\begin{tabular}{|c|c|}
\hline \multicolumn{2}{|c|}{ Parenting Practices [52] } \\
\hline \multicolumn{2}{|c|}{$\begin{array}{l}\text { Authoritarian } \\
\text { Please recall your childhood memories and inform us about your perceptions regarding the behavior of your parents for the } \\
\text { following items? }\end{array}$} \\
\hline AURIAN1 & In my childhood, my parents never allowed me to question their decisions. \\
\hline AURIAN2 & In my childhood, my parents always taught me to keep control of my feelings at all times. \\
\hline AURIAN3 & In my childhood, my parents never allowed me to say bad things about my teachers. \\
\hline AURIAN4 & In my childhood, my parents never allowed me to get angry with them. \\
\hline AURIAN5 & $\begin{array}{l}\text { In my childhood, my parents frequently gave me a good many duties and family } \\
\text { responsibilities. }\end{array}$ \\
\hline AURIAN6 & In my childhood, my parents always taught me to learn early and not to cry. \\
\hline AURIAN7 & In my childhood, my parents always instructed me not to get dirty while playing. \\
\hline \multicolumn{2}{|c|}{$\begin{array}{l}\text { Authoritative } \\
\text { Please recall your childhood memories and inform us about your perceptions regarding the behavior of your parents for the } \\
\text { following items? }\end{array}$} \\
\hline AUTIVE1 & $\begin{array}{l}\text { In my childhood, my parents always respected my opinions and encourage me to } \\
\text { express them. }\end{array}$ \\
\hline AUTIVE2 & In my childhood, my parents always encouraged me to talk about my troubles. \\
\hline AUTIVE3 & In my childhood, my parents always encouraged me to make many decisions myself. \\
\hline AUTIVE4 & $\begin{array}{l}\text { In my childhood, my parents always encouraged me to be curious, to explore and } \\
\text { question things. }\end{array}$ \\
\hline AUTIVE5 & In my childhood, my parents always appreciated for what I tried or accomplished. \\
\hline AUTIVE6 & In my childhood, my parents always encouraged me to wonder and think about life. \\
\hline AUTIVE7 & In my childhood, my parents were always strict, having well-established rules for me. \\
\hline AUTIVE8 & In my childhood, my parents and myself had warm, intimate times together. \\
\hline AUTIVE9 & In my childhood, my parents always encouraged me to do my best. \\
\hline AUTIVE10 & $\begin{array}{l}\text { In my childhood, my parents always encouraged me often took it over and reasoned with } \\
\text { me I misbehaved with them. }\end{array}$ \\
\hline AUTIVE11 & dhood, my parents always wanted me to be independent from them. \\
\hline
\end{tabular}




\begin{tabular}{|c|c|}
\hline $\begin{array}{l}\text { Training } \\
\text { Please recall } \\
\text { following ite }\end{array}$ & Idhood memories and inform us about your perceptions regarding the behavior of your parents for the \\
\hline TRG1 & My parents believed that children are by nature born good. \\
\hline TRG2 & My parents believed that child training must begin as soon as he/she is ready. \\
\hline TRG3 & $\begin{array}{l}\text { In my childhood, my parents always expressed their love for me by helping me succeed, } \\
\text { especially in school. }\end{array}$ \\
\hline TRG4 & My parents always believed that children can improve in almost anything if they work hard. \\
\hline TRG5 & My parents believed that a mother must train her child to work very hard and be disciplined. \\
\hline TRG6 & $\begin{array}{l}\text { My parents believed that a mother should teach her child by pointing out good behavior } \\
\text { in others. }\end{array}$ \\
\hline TRG7 & $\begin{array}{l}\text { My parents always believed that the best way a child learns how to behave is by being } \\
\text { around adults. }\end{array}$ \\
\hline TRG8 & $\begin{array}{l}\text { My parents believed that when a child continues to disobey you, he/she deserves } \\
\text { some punishment. }\end{array}$ \\
\hline TRG9 & My parents believed that a mother's sole interest is in taking care of her child. \\
\hline TRG10 & $\begin{array}{l}\text { In my childhood, my parents believed that children should be in the constant care of their } \\
\text { mothers or family. }\end{array}$ \\
\hline TRG11 & $\begin{array}{l}\text { In my childhood, my parents believed that a mother should do everything for her child's } \\
\text { education and make many sacrifices. }\end{array}$ \\
\hline TRG12 & $\begin{array}{l}\text { In my childhood, my parents believed that a child should be able to be with his/her mother } \\
\text { and taken on errands and gatherings. }\end{array}$ \\
\hline Sociali & Goals $[48,52,74]$ \\
\hline Socio-emot & development \\
\hline SED1 & During my childhood, my parents always wanted me to respect my elders. \\
\hline SED2 & During my childhood, my parents always wanted me to trust family members. \\
\hline SED3 & During my childhood, my parents always wanted me to achieve emotional independence. \\
\hline SED4 & $\begin{array}{l}\text { During my childhood, my parents always wanted me to feel comfortable about sharing my } \\
\text { hopes and fears with them. }\end{array}$ \\
\hline SED5 & During my childhood, my parents always wanted me to feel close to my grandparents. \\
\hline SED6 & $\begin{array}{l}\text { My parents believed that children should visit parents on traditional family celebrations, } \\
\text { even when they have their own children. }\end{array}$ \\
\hline SED7 & $\begin{array}{l}\text { During my childhood, my parents always wanted me to feel that they care about } \\
\text { my happiness. }\end{array}$ \\
\hline SED8 & $\begin{array}{l}\text { During my childhood, my parents always wanted me to learn about the importance of close } \\
\text { family ties. }\end{array}$ \\
\hline SED9 & My parents believed that, it is important for children to always get along with their siblings. \\
\hline SED10 & $\begin{array}{l}\text { During my childhood, my parents always wanted me to be helpful and considerate } \\
\text { with others. }\end{array}$ \\
\hline SED11 & $\begin{array}{l}\text { During my childhood, my parents always wanted me to share my belongings and ideas } \\
\text { with classmates. }\end{array}$ \\
\hline SED12 & During my childhood, my parents always wanted me to get along with my teachers. \\
\hline SED13 & During my childhood, my parents always wanted me to love and care for other people. \\
\hline SED14 & During my childhood, my parents always wanted me to fulfill my own hopes and wishes. \\
\hline SED15 & During my childhood, my parents always wanted me to be loved and cared for by others. \\
\hline
\end{tabular}


Children altruism $[25,75,76]$

\begin{tabular}{cc}
\hline Altruism for personal satisfaction \\
\hline APS1 & I enjoy sharing my knowledge with colleagues. \\
\hline APS2 & I feel good helping my colleagues by sharing my knowledge. \\
\hline APS3 & Sharing my knowledge with colleagues is pleasurable. \\
\hline Altruism for organizational benefits \\
\hline AOB1 & My knowledge sharing would help my company achieve its goals.; \\
\hline AOB2 & My knowledge sharing would help my company enrich its knowledge base. \\
\hline AOB3 & My knowledge sharing would help my company grow. \\
\hline Knowledge Sharing Behavior [77] \\
\hline Knowledge collecting \\
\hline KC1 & When I have learned something new, I tell my colleagues about it. \\
\hline KC2 & I share information I have with my colleagues. \\
\hline KC3 & I thinkg it is important that my colleagues know what I am doing. \\
\hline KC4 & I regularly tell my colleagues what I am doing. \\
\hline Knowledge donating
\end{tabular}

\section{References}

1. Huarng, K.H.; Ribeiro, D. Developmental management: Theories, methods, and applications in entrepreneurship, innovation, and sense-making. J. Bus. Res. 2014, 67, 657-662. [CrossRef]

2. Huarng, K.H.; Mas-Tur, A. Spirit of strategy (SOS): The new SOS for competitive business. J. Bus. Res. 2015, 68, 1383-1387. [CrossRef]

3. Huarng, K.H.; Yu, T.H.K.; Lai, W. Innovation and diffusion of high-tech products, services, and systems. J. Bus. Res. 2015, 68, 2223-2226. [CrossRef]

4. Huarng, K.H.; Mas-Tur, A. New knowledge impacts in designing implementable innovative realities. J. Bus. Res. 2016, 69, 1529-1533. [CrossRef]

5. Huarng, K.H.; Mas-Tur, A. Turning Kurt Lewin on his head: Nothing is so theoretical as a good practice. J. Bus. Res. 2016, 69, 4725-4731. [CrossRef]

6. Ribeiro, D.; Huarng, K.H. Innovation and entrepreneurship in knowledge industries. J. Bus. Res. 2013, 66, 1964-1969.

7. Davenport, T.H.; Prusak, L. Working Knowledge: How Organizations Manage What They Know; Harvard Business School Press: Boston, MA, USA, 1998.

8. Foss, N.J.; Pedersen, T. Transferring knowledge in MNCs: The role of sources of subsidiary knowledge and organizational context. J. Int. Manag. 2002, 8, 49-67. [CrossRef]

9. Grant, R.M. Toward a knowledge-based theory of the firm. Strateg. Manag. J. 1996, 17, 109-122. [CrossRef]

10. Kogut, B.; Zander, U. Knowledge of the firm, combinative capabilities, and the replication of technology. Organ. Sci. 1992, 3, 383-397. [CrossRef]

11. Nataraajan, R. Knowledge and innovation: Musings from the 2015 GIKA Ivory Tower. J. Bus. Res. 2016, 69, 3572-3575. [CrossRef]

12. Spender, J.C.; Grant, R.M. Knowledge and the firm: Overview. Strateg. Manag. J. 1996, 17, 5-9. [CrossRef] 
13. Wang, S.; Noe, R.A. Knowledge sharing: A review and directions for future research. Hum. Resour. Manag. Rev. 2010, 20, 115-131. [CrossRef]

14. Wu, C.W.; Huarng, K.H. Global entrepreneurship and innovation in management. J. Bus. Res. 2015, 68, 743-747. [CrossRef]

15. Donate, M.J.; Pablo, J.D.S. The role of knowledge-oriented leadership in knowledge management practices and innovation. J. Bus. Res. 2015, 68, 360-370. [CrossRef]

16. Nguyen, H.N.; Mohamed, S. Leadership behaviors, organizational culture and knowledge management practices: An empirical investigation. J. Manag. Dev. 2011, 30, 206-221. [CrossRef]

17. Grewal, R.; Slotegraaf, R.J. Embeddedness of organizational capabilities. Decis. Sci. 2007, 38, 451-488. [CrossRef]

18. Sinkula, J.M. Market information processing and organizational learning. J. Mark. 1994, 58, 35-45. [CrossRef]

19. Szulanski, G. Exploring internal stickiness: Impediments to the transfer of best practice within the firm. Strateg. Manag. J. 1996, 17, 27-43. [CrossRef]

20. Arthur, J.B.; Huntley, C.L. Ramping up the organizational learning curve: Assessing the impact of deliberate learning on organizational performance under gain sharing. Acad. Manag. J. 2005, 48, 1159-1170. [CrossRef]

21. Collins, C.J.; Smith, K.G. Knowledge exchange and combination: The role of human resource practices in the performance of high-technology firms. Acad. Manag. J. 2006, 49, 544-560. [CrossRef]

22. Cummings, J.N. Work groups, structural diversity, and knowledge sharing in a global organization. Manag. Sci. 2004, 50, 352-364. [CrossRef]

23. Hansen, M.T. Knowledge network: Explaining effective knowledge sharing in multiunit companies. Organ. Sci. 2002, 13, 232-248. [CrossRef]

24. Jackson, S.E.; Chuang, C.-H.; Harden, E.E.; Jiang, Y.; Joseph, J.M. Toward developing human resource management systems for knowledge-intensive teamwork. In Research in Personnel and Human Resources Management; Joseph, J.M., Ed.; Emerald Group Publishing Limited: New York, NY, USA, 2006; Volume 25, pp. 27-70.

25. Lin, H.-F. Knowledge sharing and firm innovation capability: An empirical study. Int. J. Manpow. 2007, 28, 315-332. [CrossRef]

26. Mesmer-Magnus, J.R.; DeChurch, L.A. Information sharing and team performance: A meta-analysis. J. Appl. Psychol. 2009, 94, 535-546. [CrossRef] [PubMed]

27. Babcock, P. Shedding light on knowledge management. HR Mag. 2004, 49, 46-50.

28. Chernyak, N.; Kushnir, T. Giving Preschoolers Choice Increases Sharing Behavior. Psychol. Sci. 2013. [CrossRef] [PubMed]

29. Van Acker, F.; Vermeulen, M.; Kreijns, K.; Lutgerink, J.; van Buuren, H. The role of knowledge sharing self-efficacy in sharing Open Educational Resources. Comput. Hum. Behav. 2014, 39, 136-144. [CrossRef]

30. Pulakos, E.D.; Dorsey, D.W.; Borman, W.C. Hiring for knowledge-based competition. In Managing Knowledge for Sustained Competitive Advantage: Designing Strategies for Effective Human Resource Management; Jackson, S.E., Hitt, M.A., Denisi, A.S., Eds.; Wiley: San Francisco, CA, USA, 2003.

31. Centobelli, P.; Cerchione, R.; Esposito, E. Aligning enterprise knowledge and knowledge management systems to improve efficiency and effectiveness performance: A three-dimensional Fuzzy-based decision support system. Expert Syst. Appl. 2018, 91, 107-126. [CrossRef]

32. Chen, S.; Chuang, Y.; Chen, P. Behavioral intention formation in knowledge sharing: Examining the roles of KMS quality, KMS self-efficacy, and organizational climate. Knowl.-Based Syst. 2012, 31, 106-118. [CrossRef]

33. Zhang, X.; Pablo, P.; Zhou, Z. Effect of knowledge sharing visibility on incentive-based relationship in Electronic Knowledge Management Systems: An empirical investigation. Comput. Hum. Behav. 2013, 29, 307-313. [CrossRef]

34. Pee, L.G.; Min, J. Employees' online knowledge sharing: The effects of person-environment fit. J. Knowl. Manag. 2017, 21, 432-453. [CrossRef]

35. Kang, Y.J.; Lee, J.Y.; Kim, H. A psychological empowerment approach to online knowledge sharing. Comput. Hum. Behav. 2017, 74, 175-187. [CrossRef]

36. Bordia, P.; Irmer, B.E.; Abusah, D. Differences in sharing knowledge interpersonally and via databases: The role of evaluation apprehension and perceived benefits. Eur. J. Work Organ. Psychol. 2006, 15, 262-280. [CrossRef] 
37. Gray, P.H. The impact of knowledge repositories on power and control in the workplace. Inf. Technol. People 2001, 14, 368-384. [CrossRef]

38. Hansen, M.T.; Nohria, N.; Tierny, T. What's your strategy for managing knowledge? Harv. Bus. Rev. 1999, 77, 106-116. [PubMed]

39. Erikson, E.H. Identity: Youth and Crisis; No. 7; WW Norton \& Company: New York, NY, USA, 1994.

40. Kohlberg, L. The Psychology of Moral Development: The Nature and Validity of Moral Stages; Essays on Moral Development; Harper \& Row: San Francisco, CA, USA, 1984; Volume 2.

41. Piaget, J. The Moral Judgment of the Child; Kegan Paul, Trench, Trubner \& Co.: London, UK, 1932.

42. Bronfenbrenner, U. Ecological models of human development. In International Encyclopedia of Education, 2nd ed.; Elsevier: Oxford, UK, 1994; Volume 3.

43. Oswalt, A. Child Development and Parenting: Early (3-7) Introduction-Development during Early Childhood. 2017. Available online: http:/ / www.gulfbend.org/poc/view_doc.php?type=doc\&id=12753\& cn $=462$ (accessed on 25 January 2017).

44. Premack, D.; Woodruff, G. Does the chimpanzee have a theory of mind? Behav. Brain Sci. 1978, 1, 515-526. [CrossRef]

45. Bandura, A. Social Learning Theory; Prentice Hall: Englewood Cliffs, NJ, USA, 1977.

46. Cooper, J.O.; Heron, T.E.; Heward, W.L. Applied Behavior Analysis, 2nd ed.; Pearson: Upper Saddle River, NJ, USA, 2007.

47. Armstrong, K.H.; Ogg, J.A.; Sundman-Wheat, A.N.; John, W.A. Evidence-Based Interventions for Children with Challenging Behavior; Springer: New York, NY, USA, 2014; p. 25.

48. Chen, X.; Dong, Q.; Zhou, H. Authoritative and authoritarian parenting practices and social and school performance in Chinese children. Int. J. Behav. Dev. 1997, 21, 855-875. [CrossRef]

49. McGillicudy-DeLisi, A. Parents' beliefs and children's personal-social development. In Parental Beliefs System: The Psychological Consequences for Children; McGillicudy-DeLisi, A., Sigel, I.E., Goodnow, J., Eds.; Lawrence Erlbaum: Hillsdale, NJ, USA, 1992; pp. 115-142.

50. Baumrind, D. Child care practices anteceding three patterns of preschool behavior. Genet. Psychol. Monogr. 1967, 75, 43-88. [PubMed]

51. Steinberg, L.; Elmen, J.D.; Mounts, N.S. Authoritative parenting, psychosocial maturity, and academic success among adolescents. Child Dev. 1989, 60, 1424-1436. [CrossRef] [PubMed]

52. Pearson, E.; Rao, N. Socialization goals, parenting practices, and peer competence in Chinese and English preschoolers. Early Child Dev. Care 2003, 173, 131-146. [CrossRef]

53. Strassberg, Z.; Dodge, K.A.; Bates, J.E.; Pettit, G.S. The longitudinal relation between parental conflict strategies and children's sociometric standing in kindergarten. Merrill-Palmer Q. 1992, 38, 477-493.

54. Cherry, K. What Is Permissive Parenting? 2016. Available online: https://www.verywell.com/what-ispermissive-parenting-2794957 (accessed on 27 March 2017).

55. Chao, R.K. Parenting style: Understanding Chinese parenting through the cultural notion of training. Child Dev. 1994, 65, 1111-1119. [CrossRef] [PubMed]

56. Eisenberg, N. The Socialization and Development of Empathy and Prosocial Behavior (Special Report); The National Association for Humane and Environmental Education: East Haddam, CT, USA, 1983.

57. Devanath, S. Parental Attitudes and Children's Sharing Behavior: How Socialization Related to Early Pro-Social Development. Bachelor's Thesis, Department of Psychology, University of Pittsburgh, Pittsburgh, PA, USA, 2010.

58. Takagishi, H.; Kameshima, S.; Schug, J.; Koizumi, M.; Yamagishi, T. Theory of mind enhances preference for fairness. J. Exp. Child Psychol. 2010, 105, 130-137. [CrossRef] [PubMed]

59. Wu, Z.; Su, Y. How do preschoolers' sharing behaviors relate to their theory of mind understanding? J. Exp. Child Psychol. 2014, 120, 73-86. [CrossRef] [PubMed]

60. Chevalier, A. Parental Education and Child's Education: A Natural Experiment; Discussion Paper No. 1153; The Institute for the Study of Labor (IZA): Bonn, Germany, 2004.

61. Benenson, J.F.; Pascoe, J.; Radmore, N. Children's altruistic behavior in the dictator game. Evol. Hum. Behav. 2007, 28, 168-175. [CrossRef]

62. Karmakar, R.; Ghosh, A. Altruistic behavior of adolescents in different regions of India. J. Indian Acad. Appl. Psychol. 2012, 38, 44-53. 
63. Bradley, R.H.; Corwyn, R.F. Socioeconomic Status and Child Development. Annu. Rev. Psychol. 2012, 53, 371-399. [CrossRef] [PubMed]

64. Eisenberg, N.; Fabes, R.A.; Spinrad, T.L. Pro-social development. In Handbook of Child Psychology: Vol. 3. Social, Emotional, and Personality Development, 6th ed.; Eisenberg, N., Lerner, R.M., Eds.; Wiley: Hoboken, NJ, USA, 2006; pp. 646-718.

65. Piliavin, J.A.; Charng, H.-W. Altruism: A review of recent theory and research. Annu. Rev. Sociol. 1990, 16, 27-65. [CrossRef]

66. Quinn, N. Cultural selves. Ann. N. Y. Acad. Sci. 2003, 1001, 145-176. [CrossRef] [PubMed]

67. Faul, F.; Erdfelder, E.; Lang, A.G.; Buchner, A.G. Power 3: A flexible statistical power analysis program for the social, behavioral, and biomedical sciences. Behav. Res. Methods 2007, 39, 175-191. [CrossRef] [PubMed]

68. Hair, J.F.; Hult, G.T.M.; Ringle, C.M.; Sarstedt, M. A Primer on Partial Least Squares Structural Equation Modeling (PLS-SEM), 2nd ed.; SAGE: Thousand Oaks, CA, USA, 2017.

69. Abbas, M.; Raja, U.; Darr, W.; Bouckenooghe, D. Combined effects of perceived politics and psychological capital on job satisfaction, turnover intentions, and performance. J. Manag. 2014, 40, 1813-1830. [CrossRef]

70. Butt, A.N.; Choi, J.N.; Jaeger, A.M. The effects of self-emotion, counterpart emotion, and counterpart behavior on negotiator behavior: A comparison of individual-level and dyad-level dynamics. J. Organ. Behav. 2005, 26, 681-704. [CrossRef]

71. Raja, U.; Johns, G. The joint effects of personality and job scope on in-role performance, citizenship behaviors, and creativity. Hum. Relat. 2010, 63, 981-1005. [CrossRef]

72. Naseer, S.; Raja, U.; Syed, F.; Donia, M.B.; Darr, W. Perils of being close to a bad leader in a bad environment: Exploring the combined effects of despotic leadership, leader member exchange, and perceived organizational politics on behaviors. Leadersh. Q. 2016, 27, 14-33. [CrossRef]

73. Henseler, J. Bridging design and behavioral research with variance-based structural equation modeling. J. Advert. 2017, 46, 178-192. [CrossRef]

74. Rubin, K.H.; Mills, R.S. Parents' thoughts about children's socially adaptive and maladaptive behaviors: Stability, change, and individual differences. In Parental. Belief Systems: The Psychological Consequences for Children; Psychology Press: England, UK, 1992.

75. Chiu, C.M.; Hsu, M.H.; Wang, E.T.G. Understanding knowledge sharing in virtual communities: An integration of social capital and social cognitive theories. Decis. Support Syst. 2006, 42, 1872-1888. [CrossRef]

76. Wang, W.T.; Hou, Y.P. Motivations of employees' knowledge sharing behaviors: A self-determination perspective. Inf. Organ. 2015, 25, 1-26. [CrossRef]

77. Van den Hooff, B.; Hendrix, L. Eager and Willingness to Share: The Relevance of Different Knowledge Sharing Attitudes. Available online: https://warwick.ac.uk/fac/soc/wbs/conf/olkc/archive/oklc5/papers/d-3_ hooff.pdf (accessed on 6 January 2018).

78. Rigdon, E.E.; Sarstedt, M.; Ringle, C.M. On comparing results from CB-SEM and PLS-SEM: Five perspectives and five recommendations. Mark. ZFP 2017, 39, 4-16. [CrossRef]

79. Sarstedt, M.; Hair, J.F.; Ringle, C.M.; Thiele, K.O.; Gudergan, S.P. Estimation issues with PLS and CBSEM: Where the bias lies! J. Bus. Res. 2016, 69, 3998-4010. [CrossRef]

80. van Riel, A.C.; van Riel, A.C.; Henseler, J.; Henseler, J.; Kemény, I.; Kemény, I.; Sasovova, Z. Estimating hierarchical constructs using consistent partial least squares: The case of second-order composites of common factors. Ind. Manag. Data Syst. 2017, 117, 459-477. [CrossRef]

81. Wright, R.T.; Campbell, D.E.; Thatcher, J.B.; Roberts, N. Operationalizing Multidimensional Constructs in Structural Equation Modeling: Recommendations for IS Research. Comun. Assoc. Inf. Syst. 2012. Available online: http:/ / aisel.aisnet.org/cgi/viewcontent.cgi?article=3665\&context=cais (accessed on 6 January 2018).

82. Becker, J.M.; Klein, K.; Wetzels, M. Hierarchical latent variable models in PLS-SEM: Guidelines for using reflective-formative type models. Long Range Plan. 2012, 45, 359-394. [CrossRef]

83. Astrachan, C.B.; Patel, V.K.; Wanzenried, G. A comparative study of CB-SEM and PLS-SEM for theory development in family firm research. J. Fam. Bus. Strategy 2014, 5, 116-128. [CrossRef]

84. Hair, J.F.; Sarstedt, M.; Ringle, C.M.; Gudergan, S.P. Advanced Issues in Partial Least Squares Structural Equation Modeling; SAGE Publishing: Thousand Oaks, CA, USA, 2017.

85. Henseler, J.; Hubona, G.; Ray, P.A. Using PLS path modeling in new technology research: Updated guidelines. Ind. Manag. Data Syst. 2016, 116, 2-20. [CrossRef] 
86. Richter, N.F.; Cepeda, G.; Roldán, J.L.; Ringle, C.M. European management research using partial least squares structural equation modeling (PLS-SEM). Eur. Manag. J. 2015, 33, 1-3. [CrossRef]

87. Sarstedt, M.; Ringle, C.M.; Hair, J.F. Partial least squares structural equation modeling. In Handbook of Market Research; Homburg, C., Klarmann, M., Vomberg, A., Eds.; Springer International Publishing: Cham, Switzerland, 2017; pp. 1-40.

88. Ringle, C.M.; Wende, S.; Becker, J.M. SmartPLS 3. Bönningstedt: SmartPLS. 2015. Available online: http: / / www.smartpls.com (accessed on 2 May 2017).

89. Chin, W.W. How to write up and report PLS analyses. In Handbook of Partial Least Squares: Concepts, Methods and Applications; Esposito Vinzi, V., Chin, W.W., Henseler, J., Wang, H., Eds.; Springer: Berlin/Heidelberg, Germany, 2010; pp. 655-690.

90. Hair, J.F.; Sarstedt, M.; Ringle, C.M.; Mena, J.A. An assessment of the use of partial least squares structural equation modeling in marketing research. J. Acad. Mark. Sci. 2012, 40, 414-433. [CrossRef]

91. Roldán, J.L.; Sánchez-Franco, M.J. Variance-based structural equation modeling: Guidelines for using partial least squares. In Research Methodologies, Innovations and Philosophies in Software Systems Engineering AND Information Systems; Mora, M., Gelman, O., Steenkamp, A., Raisinghani, M.S., Eds.; IGI Global: Hershey, PA, USA, 2012; pp. 193-221.

92. Fornell, C.; Larcker, D. Evaluating structural equation models with unobservable variables and measurement error. J. Mark. Res. 1981, 18, 39-50. [CrossRef]

93. Nunnally, J. Psychometric Theory; McGraw-Hill: New York, NY, USA, 1978.

94. Hair, J.F.; Andersson, R.E.; Tatham, R.L.; Black, W.C. Multivariate Data Analysis; Prentice Hall: Homewood, NJ, USA, 1998.

95. Gefen, D.; Straub, D. A Practical Guide to Factorial Validity Using PLS-Graph: Tutorial and Annotated Example. Commun. Assoc. Inf. Syst. 2005, 16, 91-105.

96. Henseler, J.; Ringle, C.M.; Sarstedt, M. A new criterion for assessing discriminant validity in variance-based structural equation modeling. J. Acad. Mark. Sci. 2015, 43, 115-135. [CrossRef]

97. Becker, J.M.; Rai, A.; Rigdon, E. Predictive Validity and Formative Measurement in Structural Equation Modeling: Embracing Practical Relevance. In Proceedings of the Thirty Fourth international Conference on Information Systems, Milan, Italy, 15-18 December 2013; pp. 1-19.

98. Hulland, J. Use of partial least squares (PLS) in strategic management research: A review of four recent studies. Strateg. Manag. J. 1999, 20, 195-204. [CrossRef]

99. Kock, N. One-tailed or two-tailed P values in PLS-SEM? Int. J. e-Collab. 2015, 11, 1-7. [CrossRef]

100. Chin, W. Issues and opinion on structural equation modeling. MIS Q. 1998, 22, 7-16.

101. Henseler, J.; Dijkstra, T.K.; Sarstedt, M.; Ringle, C.M.; Diamantopoulos, A.; Straub, D.W.; Calantone, R. Common beliefs and reality about PLS: Comments on Rönkkö \& Evermann (2013). Organ. Res. Methods 2014, 17, 182-209.

102. Hu, L.T.; Bentler, P.M. Cutoff criteria for fit indexes in covariance structure analysis: Conventional criteria versus new alternatives. Struct. Equ. Model. Multidiscip. J. 1999, 6, 1-55. [CrossRef]

103. Armstrong, J.S. Illusions in regression analysis. Int. J. Forecast. 2012, 28, 689-694. [CrossRef]

104. Shmueli, G.; Ray, S.; Velasquez Estrada, J.M.; Chatla, S.B. The elephant in the room: Predictive performance of PLS models. J. Bus. Res. 2016, 69, 4552-4564. [CrossRef]

105. Woodside, A.G. Moving beyond multiple regression analysis to algorithms: Calling for adoption of a paradigm shift from symmetric to asymmetric thinking in data analysis and crafting theory. J. Bus. Res. 2013, 66, 463-472. [CrossRef]

106. Ali, M.; Seny Kan, A.K.; Sarstedt, M. Direct and configurational paths of absorptive capacity and organizational innovation to successful organizational performance. J. Bus. Res. 2016, 69, 5317-5323. [CrossRef]

107. Ali, Z.; Sun, H.; Ali, M. The Impact of Managerial and Adaptive Capabilities to Stimulate Organizational Innovation in SMEs: A Complementary PLS-SEM Approach. Sustainability 2017, 9, 2157. [CrossRef]

108. Ali, I.; ul Musawir, A.; Ali, M. Impact of knowledge sharing and absorptive capacity on project performance: The moderating role of social processes. J. Knowl. Manag. 2018, in press.

109. Felipe, C.M.; Roldán, J.L.; Leal-Rodríguez, A.L. Impact of Organizational Culture Values on Organizational Agility. Sustainability 2017, 9, 2354. [CrossRef] 
110. Salam, M.A.; Ali, M.; Seny Kan, A.K. Analyzing Supply Chain Uncertainty to Deliver Sustainable Operational Performance: Symmetrical and Asymmetrical Modeling Approaches. Sustainability 2017, 9, 2217. [CrossRef]

111. Cepeda Carrión, G.; Henseler, J.; Ringle, C.M.; Roldán, J.L. Prediction-oriented modeling in business research by means of PLS path modeling: Introduction to a JBR special section. J. Bus. Res. 2016, 69, 4545-4551. [CrossRef]

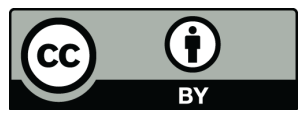

(C) 2018 by the authors. Licensee MDPI, Basel, Switzerland. This article is an open access article distributed under the terms and conditions of the Creative Commons Attribution (CC BY) license (http:/ / creativecommons.org/licenses/by/4.0/). 